\title{
Correlating the speed of sound to Gibbs energy and estimation of the speed of sound in fatty acid methyl ester and biodiesel
}

\author{
Apinya Cheewaphan ${ }^{1}$, Ubol Chuensumran ${ }^{2}$, Suriya Phankosol $^{3}$, Kornkanok Aryusuk $^{1}$, \\ Supathra Lilitchan ${ }^{4}$, and Kanit Krisnangkura ${ }^{5}$ \\ ${ }^{1}$ King Mongkut's University of Technology Thonburi \\ ${ }^{2}$ Suan Dusit University \\ ${ }^{3}$ Bansomdejchaopraya Rajabhat University \\ ${ }^{4}$ Mahidol University \\ ${ }^{5}$ King Mongkut's University of Technology Thonburil
}

July 14, 2020

\begin{abstract}
The relationship between the speed of sound (u) in biodiesel and the change in Gibbs energy $(\Delta \mathrm{G})$ has not been describe in literature. With the Gibbs energy additivity (GEA ) method, the relation between $\mathrm{u}$ and $\Delta \mathrm{G}$ can be expressed as lnu2 $=$ $\Delta \mathrm{G} / \mathrm{RT}+\mathrm{A}$, where $\mathrm{R}$ is the universal gas constant; $\mathrm{T}$ is absolute temperature and $\mathrm{A}$ is constant. Further expansion of the ?G to its enthalpy and entropy, and sub-division the molecule of a fatty and methyl ester (FAME) into groups of atoms, the final model was good for estimation the speed of sound in both FAME and biodiesel at various temperatures. Only numbers of double bond and carbon atoms of fatty acid were required for the calculation.
\end{abstract}

\section{Hosted file}

Speed of sound 3.docx available at https://authorea.com/users/342701/articles/469546correlating-the-speed-of-sound-to-gibbs-energy-and-estimation-of-the-speed-of-soundin-fatty-acid-methyl-ester-and-biodiesel 


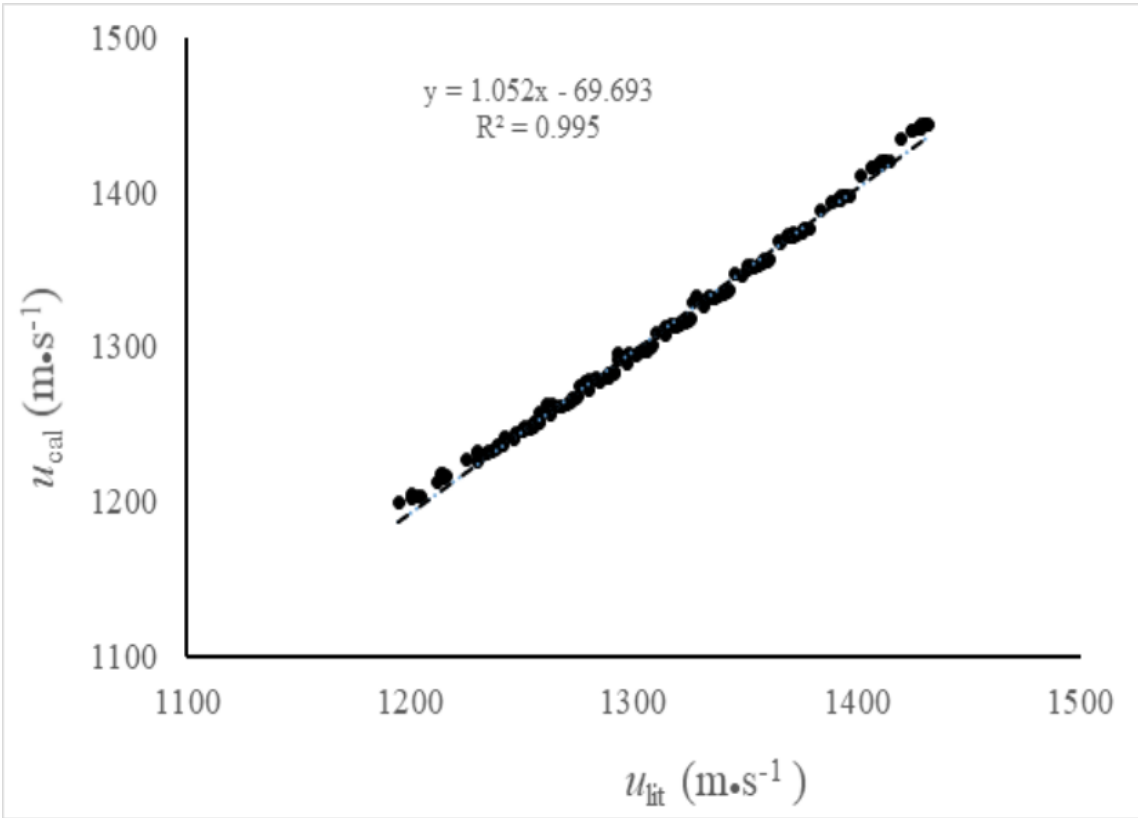

